\title{
De margem em margem, de tropeço em tropeço
}

\section{Flávia Merighi Valenciano ${ }^{1}$}

RESUMO: Este ensaio tem por finalidade realizar um estudo comparado entre três personagens femininas socialmente marginalizadas: Dina, de José Luandino Vieira, Mariazinha tiro a esmo, de João Antônio, e Dama da noite, de Caio Fernando Abreu.

ABSTRACT: This essay aims to accomplish a comparative study between three socially marginalized female characters: Dina, by José Luandino Vieira; Mariazinha tiro a esmo, by João Antônio; and Dama da Noite, by Caio Fernando Abreu.

PALAVRAS-CHAVE: Literatura; estudos comparados; língua portuguesa; marginalidade.

KEYWORDS: Literature; comparative study; Portuguese language; marginality.

Este estudo pretende realizar uma comparação entre personagens femininas pertencentes aos contos de três escritores de língua portuguesa. Tais textos possuem tanto similaridades contextuais quanto similaridades situacionais passíveis de comparação, já que retratam personagens e temas semelhantes e são frutos de ex-colônias portuguesas, possuindo, portanto, a mesma língua matriz.

A primeira personagem, Dina, faz parte do conto homônimo, pertencente ao livro Vidas Novas, do escritor angolano José Luandino Vieira. Sua primeira publicação foi no ano de 1964, em Paris, pelas Edições Anti-Colonial, sendo que a primeira edição legal, revista pelo autor, foi publicada somente em 1975, pela Editora Afrontamento do Porto. A segunda personagem é Mariazinha, de "Mariazinha tiro a esmo", conto do escritor brasileiro João Antônio, que pertence ao livro Malhação do Judas Carioca, publicado pela primeira vez em 1975, pela Editora Civilização Brasileira. Por fim, Dama da noite, personagem do conto homônimo de Os dragões não conhecem o paraíso, do escritor brasileiro Caio Fernando Abreu, publicado no ano de 1986, pela Companhia das Letras.

A princípio, o que nos chama a atenção em tais contos é o modo como os autores utilizam a língua portuguesa, o que retrata a condição das personagens e torna-se um dos

\footnotetext{
${ }^{1}$ Mestranda em Estudos Comparados de Literaturas de Língua Portuguesa, FFLCH-USP. Pesquisa: Travessias solitárias: um estudo sobre as personagens de João Antônio e Caio Fernando Abreu. E-mail: flaviamerighi@usp.br.
} 
principais instrumentos na luta contra a opressão e o preconceito. Para compor sua personagem e o contexto sócio-político-cultural em que se encontra - uma prostituta que vive no Santo Rosa, um musseque da cidade de Luanda -, Luandino Vieira utiliza-se do quimbundo e do português dialetizado. Assim, constrói uma "língua angolana" peculiar, que foge aos padrões da língua do colonizador. O narrador utiliza-se de um vocabulário que causa estranheza a qualquer leitor que desconheça a realidade de Angola:

Alegria como ainda com esses olhos grandes, lá em cima da torre deles, de ferro com tinta de alumínio, que mijavam a luz amarela nas areias vermelhas dos musseques, despindo cubatas, sombras boas de cambular fregueses (...) (destaque meu). ${ }^{2}$

Além do quimbundo, é marcante a presença da linguagem coloquial, especialmente nas falas das personagens. A história de Dina é construída pela linguagem dos socialmente marginalizados:

- Sukuama! Menina de vinte anos parece é uma acabada. Se você queres eu vou lá te ensinar ainda... ${ }^{3}$

Maluca de dor, xinguilando, a berrar, dentes para morder, Dina correu nos polícias, pelejando, insultando:

- Mataram-lhe! Eu vi, mataram-lhe! Filhos da puta! ${ }^{4}$

Em sua maioria, o texto é constituído pela língua portuguesa de Portugal; no entanto, é impregnado pela linguagem oral do povo angolano. Segundo Maria Aparecida Santilli, ao recuperar o falar cotidiano que a pretensão dos gramáticos teria querido eliminar da língua escrita, o sermo plebeius opera no texto como des-hierarquizador, tanto social quanto cultural (2003:63).

Em relação ao conto "Mariazinha tiro a esmo", o autor utiliza-se da linguagem oral e das gírias provindas da população marginalizada que ocupa os morros cariocas e os bairros mais pobres: "Dissimulada em seu trabalho, matreira trabalhando na boca do mocó, indo e vindo na baba de quiabo, enganando otários e pacatos, ela sobrevive" (destaque meu). ${ }^{5}$

\footnotetext{
${ }^{2}$ VIEIRA, José Luandino. “Dina”. In: Vidas Novas. Lisboa: Edições 70, 1997, p.13.

${ }^{3}$ Idem, ibidem, p.14.

${ }^{4}$ Idem, ibidem, p.18.

5 ANTÔNIO, João. "Mariazinha tiro a esmo". In: Malhação do Judas Carioca. Rio de Janeiro: Civilização Brasileira, 1976, p.05.
} 
Além das expressões e gírias destacadas nos trechos acima, há ainda um extenso vocabulário que escapa ao português padrão, como por exemplo "chapinha", "cocoreco", "olheira" e "piniqueira".

A personagem de Caio Fernando Abreu refere-se à "roda da vida" como alguém que está de fora dela, já que é uma prostituta que se encontra à margem da sociedade. O que nos chama a atenção, portanto, é a metáfora que escolhe para explicar sua situação:

A vida rodando por aí feito roda-gigante, com todo mundo dentro, e eu aqui parada, pateta, sentada no bar. Sem fazer nada, como se tivesse desaprendido a linguagem dos outros. A linguagem que eles usam para se comunicar quando rodam assim e assim por diante nessa roda-gigante (destaque meu) ${ }^{6}$

No trecho acima, o autor utiliza a linguagem como metáfora do status social: a prostituta sabe que está fora da "roda" porque desaprendeu a "linguagem dos outros", ou seja, não está mais inserida no mesmo contexto. Assim, a fala da Dama da noite é marcada por gírias e expressões próprias da geração dos anos 80:

Nada, você não entende nada. Dama da noite, todos me chamam e nem sabem que durmo o dia inteiro. Não suporto luz, também nunca tenho nada pra fazer - o quê? Umas rendas aí. É, macetes. Não dou detalhe, adianta insistir. ${ }^{7}$

Fora da roda, montada na minha loucura. Parada pateta ridícula porra-louca solitária venenosa. Pós-tudo, sabe como? Darkérrima, modernésima, puro simulacro. ${ }^{8}$

Outra característica da fala dessa personagem é a presença constante de palavras de baixo calão:

Se eu tô tesuda e você anda duro e eu precisar de cacete, compro o teu, pago o teu. Quanto custa? Me diz que eu pago. Pago bebida, comida, dormida. E pago foda também, se for preciso (destaque meu). ${ }^{9}$

Cuidado comigo: eu sou a dama que mata, boy. Já chupou buceta de mulher? Claro que não, eu sei: pode matar. Nem caralho de homem: pode matar (...) Punheta pode, eu sei, mas essa sede de outro corpo é que nos deixa loucos e vai matando a gente aos pouquinhos (destaque meu). ${ }^{10}$

\footnotetext{
${ }^{6}$ ABREU, Caio Fernando. "Dama da noite". In: Os dragões não conhecem o paraíso. São Paulo: Companhia das Letras, 1988, p.91.

${ }^{7}$ Idem, ibidem, p.92.

${ }^{8}$ Idem, ibidem, p.98.

${ }^{9}$ Idem, ibidem, p.92.

${ }^{10}$ Idem, ibidem, p.95.
} 
Por fim, uma marca estilística fundamental no conto de Caio são os "diálogos" que a Dama mantém com o jovem, cujas falas são omitidas no texto. No entanto, o leitor reconhece a existência de um diálogo tanto pela evidência de um interlocutor a quem a Dama chama por "boy" quanto pelas perguntas e respostas do mesmo implícitas no texto:

Mas acho que essa moçada tá mais a fim mesmo é de absorver, chupar até o fundo do mal - hein? Depois, até posso. Tem problema, não. Mas não é disso que estou falando agora, meu bem. ${ }^{11}$

Ô boy, esse mundo sujo todo pesando em cima de você, muito mais do que de mim -e eu ainda nem comecei a falar na morte... ${ }^{12}$

Não podemos afirmar exatamente o que o autor pretendia alcançar omitindo as falas do boy. Fica clara, porém, sua intenção de destacar a Dama da noite, que expõe seus sentimentos e revela suas experiências. $\mathrm{O}$ conto oferece ao leitor um mundo visto exclusivamente através dos olhos de um excluído social.

Conclui-se, portanto, que em todos os contos há a presença de características próprias da oralidade e do português coloquial, fato que lhes atribui a função de denúncia social, já que revelam a linguagem das camadas excluídas da sociedade. Nas palavras de Santilli:

Como declaradamente instaurados em transgressão, esses textos consumam-se na experiência estética que emerge de forma inesperada, de surpresa por se esquivarem às proibições. Com os riscos implícitos de qualquer gesto em marginalidade, logram, por outro lado, seu saldo: o de defesa à opressão social (2003:64, destaque meu).

A segunda característica comum entre textos e a mais relevante para que se realize este estudo é a existência de personagens que são socialmente excluídos: nos três casos, as personagens se prostituem para sobreviver.

A personagem de Luandino Vieira é mais uma entre tantas retratadas pelo autor: uma pessoa comum, do povo, que se recusa a viver no sistema dominante, o qual impossibilita uma igualdade social. Trabalhando como prostituta no musseque de Santo Rosa - fato que evidencia sua condição social, assim como sua ferida que não para de coçar -, Dina não consegue ficar feliz diante da situação em que se encontra seu povo. Ainda sob o domínio dos portugueses, a população angolana sonha com a liberdade e sofre nas mãos dos "tropas", policiais repressores que controlavam os angolanos. O tema da luta pela libertação de Angola

${ }^{11}$ Idem, ibidem, p.92.

${ }^{12}$ Idem, ibidem, , p.95. 
é recorrente na obra de Luandino, já que o autor militou a favor da guerra de libertação, escrevendo seu livro Vidas Novas enquanto estava preso no Pavilhão Prisional da PIDE, em Luanda.

A menina Dina não consegue viver em paz em meio a tanta morte e tanta injustiça, em um tempo onde "a luz amarela (...) dos quatro olhos dos projectores"13 invadem os musseques. Há algo dentro dela que parece um bicho, que a corrói por dentro e que cresce quando pensa nas "pessoas estendidas na areia, no capim, nos primeiros dias da confusão, bocas abertas para o céu da manhã, olhos a mirarem o que já não viam (...)". ${ }^{14}$ Sempre tinha um "princípio de nojo" quando se deitava com os tropas, "tinha qualquer coisa dentro dela que não aceitava". ${ }^{15}$ Em meio a seus pensamentos, relembra a morte de seus pais, assassinados pela polícia. Todos esses sentimentos - raiva, nojo, dor, medo, revolta - convidam Dina à luta, que tem como estopim a morte de um velho, cujos "olhos grossos do medo brilham parece é brasas $(\ldots.){ }^{16}$

Dina parte para o meio da confusão, sentindo "o bicho dentro dela roer": ${ }^{17}$ toda a sua raiva contra aqueles que oprimem seus semelhantes. Ao insultar os policiais, Dina apanha. Porém, acorda - finalmente - em paz, pois "dentro do corpo dela, aquele bicho tinha parado de roer", ${ }^{18}$ pois brigou por um povo injustiçado, simbolizado na figura do velho que morre pelas mãos dos policiais, na figura dela mesma e de seus pais. Em paz, enfim, pois não vai mais se deitar com os tropas, um peso tão grande que carregava.

Assim como "Dina", o conto "Mariazinha tiro a esmo" é narrado em terceira pessoa. No entanto, fica clara a diferença entre os dois: o narrador do primeiro demonstra uma extrema cumplicidade com relação à personagem enquanto o do segundo mantém-se mais distante. Um traço importante do narrador do conto de João Antônio é que o mesmo dá voz à personagem, característica típica do gênero jornalístico, assim como dados estatísticos:

Só ou acompanhada na marginalidade, vai beirando o crime na cidade que castiga para mais de quatro milhões de habitantes, mais de um milhão de favelados (destaque meu). ${ }^{19}$

\footnotetext{
${ }^{13}$ VIEIRA, José Luandino. “Dina”. In: Vidas Novas. Lisboa: Edições 70, 1997, p.14.

${ }^{14}$ Idem, ibidem, p. 15.

${ }^{15}$ Idem, ibidem, p. 15.

${ }^{16}$ Idem, ibidem, p. 17.

${ }^{17}$ Idem, ibidem, p.17.

${ }^{18}$ Idem, ibidem, p.18.

19 ANTÔNIO, João. "Mariazinha tiro a esmo". In: Malhação do Judas Carioca. Rio de Janeiro: Civilização Brasileira, 1976, p.05.
} 
e a presença do depoimento, que aparece no conto para corroborar os fatos narrados:

(...) Ela assistiu ao primeiro crime quando tinha sete anos:

- Meu neguinho, foi mais ou menos assim (....). ${ }^{20}$

O narrador inicia seu relato apresentando ao leitor Mariazinha, uma prostituta carioca conhecida pela malandragem por Mariazinha tiro a esmo, que possui a malícia necessária para sobreviver nos bairros pobres do Rio de Janeiro.

A condição social da personagem fica clara ao leitor logo no início do texto: Mariazinha conseguiu seu nome "lá pelos altos encardidos da Favela da Rocinha"21 e tem os dentes podres - característica semelhante à ferida de Dina. A menina, no entanto, não possui a mesma vontade de lutar por um ideal comum, como a personagem de Luandino: luta somente pela própria sobrevivência, assim como todos que a cercam. Vivendo no mundo da malandragem, utiliza-se dela para sobreviver:

A garotinha lhe entrega dinheiro e Maria lhe passa mais cinco pacotinhos de drops. Maria é olheira daquele trecho de Copacabana e responsável por seis meninas pedintes $(\ldots){ }^{22}$

Aos nove anos fez o primeiro crime: meteu gilete no escorregador de uns meninos que a surravam. ${ }^{23}$

Porém, dentro da "cidade que castiga", 24 vivendo à margem, Mariazinha é obrigada a ser "inflexível com as leis e a ética da malandragem". ${ }^{25}$ Seu humor carioca é "antes uma forma de driblar os percalços do que de fazer graça", ${ }^{26}$ e a menina vive a típica situação do malandro: em um dia a fartura; no outro, a miséria. Quando a chamam de piranha, diz que não tem culpa, já que ser prostituta é a melhor escolha dentro de suas possibilidades.

A Dama da noite também tem consciência de que não pertence aos estratos sociais mais abastados da sociedade brasileira. No início do conto, afirma que gostaria de pertencer ao que ela chama de "roda da vida": "Olhando de fora, a cara cheia, louca de vontade de estar

\footnotetext{
${ }^{20}$ Idem, ibidem, p.07.

${ }^{21}$ Idem, ibidem, p.05.

${ }^{22}$ Idem, ibidem, p.06.

${ }^{23}$ Idem, ibidem, p.08.

${ }^{24}$ Idem, ibidem, p.05.

${ }^{25}$ Idem, ibidem, p. 06

${ }^{26}$ Idem, ibidem, p.06.
} 
lá, rodando junto com eles nessa roda idiota (...)". 27 Porém, mais adiante, a prostituta reconsidera o que havia dito: "E até me pergunto se não é sorte também estar do lado de fora dessa roda besta que roda sem fim, sem mim. No fundo, tenho nojo dela (...)". ${ }^{28}$

No entanto, toda a fala da personagem está impregnada de dor, tristeza e amargura. Por isso, agarra-se a seu único argumento favorável: sua geração soube aproveitar melhor a juventude do que a de seu interlocutor. Sua vida, contudo, está carregada de tristeza e dor, causadas pela solidão:

Deixa você passar dos trinta, trinta e cinco, ir chegando nos quarenta e não casar e nem ter esses monstros que eles chamam de filhos, casa própria nem porra nenhuma. Acordar no meio da tarde, de ressaca, olhar sua cara arrebentada no espelho. Sozinho em casa, sozinho na cidade, sozinho no mundo. Vai doer tanto, menino. ${ }^{29}$

e por ter presenciado a morte:

Feia, tão feia a morte, boy. A pessoa fica meio verde, sabe? Da cor quase assim desse molho de espinafre frio. Mais clarinho um pouco, mas isso nem é o pior. Tem uma coisa que já não está mais ali, isso é o mais triste. Você olha, olha e olha e o corpo fica assim que nem uma cadeira. Uma mesa, um cinzeiro, um prato vazio. Uma coisa sem nada dentro. ${ }^{30}$

Todavia, é no último parágrafo do conto que percebemos a fragilidade da personagem, que se protege na noite - o que dá ainda mais sentido ao seu codinome - e sonha com "O Verdadeiro Amor": ${ }^{31}$

Só por ele, por esse que ainda não veio, te deixo essa grana agora, precisa troco não, pego a minha bolsa e dou o fora já. Está quase amanhecendo, boy. As damas da noite recolhem seu perfume com a luz do dia. Na sombra, sozinhas, envenenam a si próprias com loucas fantasias (...) Dá minha jaqueta, boy, que faz um puta frio lá fora e quando chega essa hora da noite eu me desencanto. Vivo outra vez aquilo que sou todo dia, fechada sozinha perdida no meu quarto, longe da roda e de tudo: uma criança assustada. $^{32}$

${ }^{27}$ ABREU, C. F. "Dama da noite". In: Os dragões não conhecem o paraíso. São Paulo: Companhia das Letras, 1988, p.91.

${ }^{28}$ Idem, ibidem, p.94.

${ }^{29}$ Idem, ibidem, p.93.

${ }^{30}$ Idem, ibidem, p.96.

${ }^{31}$ Ocorre exatamente o mesmo com Mariazinha.

${ }^{32}$ Idem, ibidem, p. 98 . 


\section{$O$ individual e o coletivo nas personagens}

Realizado o estudo comparativo, concluímos que além dos três escritores trabalharem em seus textos com uma linguagem oral provinda de seus respectivos contextos sóciohistórico-culturais, destacam-se em seus textos personagens marginalizadas, manifestando, assim, um compromisso social voltado à contestação de males como a discriminação social, a discriminação racial e a repressão.

Contudo, há uma diferença com relação às ações das personagens analisadas que diz respeito a uma vontade coletiva, historicamente determinada. Segundo Hegel:

Somos seres históricos e culturais. Isso significa que, além de nossa vontade individual subjetiva (...), existe uma outra vontade, muito mais poderosa, que determina a nossa: a vontade objetiva, inscrita nas instituições ou na cultura (...) (apud CHAUI, 2003:318)

E continua:

A vontade objetiva é uma vontade impessoal, coletiva, social, pública e historicamente determinada [e tem] a moralidade como sistema regulador da vida coletiva por meio (...) dos costumes e dos valores de uma sociedade, numa época determinada (...) A vida ética é o acordo e a harmonia entre a vontade subjetiva individual e a vontade objetiva cultural (apud CHAUI, 2003:318, destaque meu).

Assim, a atitude de Dina possui o acordo e a harmonia citados acima, já que seu desejo é reverter a situação vigente em seu país, assim como o de todos os angolanos daquele contexto sócio-histórico-cultural específico. Dina revolta-se, a princípio, por ter que se deitar novamente com um tropa, mas parte para a ação quando presencia a morte de um velho, provavelmente considerado uma ameaça pela PIDE. A personagem de Luandino Vieira é guiada por um sentimento de coletividade e por um desejo de transformação de sua realidade. Maria Aparecida Santilli corrobora essa afirmação:

Pelos denominadores comuns, seus angolanos se reconhecem como tal e estabelecem entre si os vínculos, fortalecidos no sentimento de solidariedade que oferece sustentação à resistência coletiva, organizada, e viabiliza sua libertação (1985:18).

Porém, no que se refere às outras personagens, não há essa harmonia entre as duas vontades: Mariazinha desrespeita a vontade objetiva seguindo a ética da malandragem, que nada tem de coletiva, já que vive em uma sociedade, em que ganha quem for mais esperto e 
quem souber trapacear; a Dama, por sua vez, relaciona-se de maneira passiva no contexto sócio-histórico-cultural no qual se insere, prendendo-se a uma geração que ficou no passado.

Atentemos ao que afirma Arno Münster com relação ao conceito de utopia desenvolvido por Ernst Bloch:

O termo "utopia" caracteriza um modelo abstrato e imaginário de um Estado, de uma sociedade, no qual são projetados todas as aspirações e sonhos de uma sociedade mais justa (...) Sua crítica não é exclusivamente uma crítica materialista destes fenômenos específicos da superestrutura que são as utopias, os sonhos e as projeções imaginárias (...). Bloch sublinha o caráter positivo destes produtos da imaginação social, sua força criadora e "subversiva", porém, num sentido construtivo, anunciador e antecipador de uma vontade futura mais firme e clara da emancipação, da reconstrução da sociedade segundo ideais de igualdade, de dignidade humana, de fraternidade e de liberdade (MÜNSTER, 1993:23 e 24, destaque meu).

Partindo desse conceito, tanto o texto quanto a personagem de Luandino Vieira podem ser considerados utópicos, pois buscam mudanças com relação a seu contexto sóciohistórico-cultural. O escritor angolano busca essa transformação da sociedade que propõe a utopia de Bloch: de país colonizado, Angola se tornaria um país independente, livre dos

colonizadores portugueses. É para alcançar tal objetivo que Dina vence seu medo e enfrenta os tropas.

No entanto, nos textos e nas personagens de João Antônio e Caio Fernando Abreu encontramos uma relação mais direta com o passado e com o presente, que remetem a uma certa nostalgia e a um imediatismo quase que necessário, já que as duas prostitutas lutam diariamente pela sobrevivência. Assim, tais textos e personagens podem ser considerados melancólicos, pois não buscam solução alguma para a situação vigente e não enxergam possibilidade alguma de transformação de sua realidade.

Desse modo, a menina Dina, impulsionada tanto por uma vontade individual quanto coletiva, busca mudar a sua realidade e a de seu povo, o que a difere das outras duas personagens analisadas, que aceitam a realidade tal como é e sobrevivem de acordo com a ética da malandragem.

\section{Referências bibliográficas}

ABREU, Caio Fernando. Dama da Noite. In: Os dragões não conhecem o paraíso. São Paulo: Companhia das Letras, 1988. 
ANTÔNIO, João. Mariazinha tiro a esmo. In: Malhação do Judas Carioca. Rio de Janeiro: Civilização Brasileira, 1976.

CHAUI, Marilena. A filosofia moral. In: Convite à filosofia. São Paulo, Editora Ática, 2003.

MÜNSTER, Arno. Ernst Bloch e o novo espírito utópico. In: Filosofia da práxis e utopia concreta. São Paulo: Edunesp, 1993.

SANTILLI, Maria Aparecida. Três literaturas distintas. In: Estórias Africanas. São Paulo: Editora Ática, 1985.

SANTILLI, Maria Aparecida. Literaturas em português: poética e gramática. In: Paralelas $e$ Tangentes entre Literaturas de Língua Portuguesa. São Paulo: Editora Arte \& Ciência, 2003.

VIEIRA, José Luandino. Dina. In: Vidas Novas. Lisboa: Edições 70, 1997. 